\title{
Endometriotic rectosigmoid stricture- a rare clinical entity
}

\section{Kuppusamy B. ${ }^{1}$, Misra S. ${ }^{2 *}$}

DOI: https://doi.org/10.17511/ijoso.2020.i01.11

\footnotetext{
$\mathbf{1}$ Balu Kuppusamy, Consultant, Department of Surgical Gastroenterologist, PSG Hospitals and IMSR, Coimbatore, Tamil Nadu, India.

2* Shivanshu Misra, Surgical Gastroenterologist and Advanced Laparoscopic Surgeon, GEM Hospital and Research Center, Coimbatore, Tamil Nadu, India. https://orcid.org/0000-0001-5160-6211
}

Endometriosis is defined as the presence of endometrial mucosa implanted in locations other than the uterine cavity. Endometriosis is usually a disease involving women of reproductive age. A probable estimate is that $510 \%$ of women in their reproductive age have endometriosis. When they do occur, women experience mostly dysmenorrhea, heavy or irregular periods, pelvic pain or dyspareunia. The most common sites for endometriosis are the ovaries $(60 \%)$, uterosacral ligament $(60 \%)$, posterior cul-de-sac $(28 \%)$, broad ligament $(15 \%)$, bladder $(15 \%)$ and sigmoid colon (7\%). Colonic endometriosis is a rare sequelae. It usually presents vaguely with nonspecific abdominal pain, dyspareunia, tenesmus, rectal bleeding or painful defecation. Laparoscopy is considered the best diagnostic modality for endometriosis with a sensitivity of $97 \%$ and specificity of $77 \%$. Although there are some rare cases of large bowel obstruction due to endometriosis in pre-menopausal women, it is extremely rare in the postmenopausal group. Our report highlights such a case, mimicking a malignant rectosigmoid stricture leading to a large bowel obstruction with minimal extracolonic endometriosis involvement. Conclusion: This case report shows that colonic endometriosis, although rare, can be significantly infiltrative and lead to complications such as a large bowel obstruction. Very rarely, isolated colonic involvement without pelvic endometriosis can mimic malignant obstruction as in this patient. Diagnosing this condition can be challenging and usually requires histological confirmation.

Keywords: Isolated sigmoid endometriosis, Bowel obstruction, CT colonogram, rare case

Corresponding Author

Shivanshu Misra, Surgical Gastroenterologist and Advanced Laparoscopic Surgeon, GEM Hospital and Research Center, Coimbatore, Tamil Nadu, India. Email: shivanshu_medico@rediffmail.com
How to Cite this Article

Kuppusamy B, Misra S. Endometriotic rectosigmoid stricture- a rare clinical entity. Surgical Review Int J Surg Trauma Orthoped. 2020;6(1):60-63.

Available From

https://surgical.medresearch.in/index.php/ijoso/artic le/view/152
To Browse

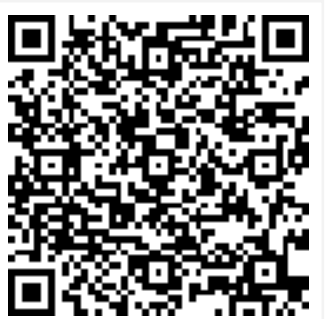

\section{Introduction}

Gastrointestinal endometriosis was first described by Dr. John A Sampson. Involvement of gastro-intestinal tract has been found in around $5-32 \%$ of the patients with endometriosis.

Manuscript Received 06-01-2020

Conflict of Interest No
Retrograde menstruation was the postulated etiology of this disease. Menstrual blood carries with it some living cells from the lining of the uterus which come to lie on the surfaces of the pelvis where they attach, implant, grow, and develop into endometriosis [1-5].

Review Round 2 24-01-2020

Ethical Approval Yes
Review Round 3

Plagiarism X-checker $17 \%$
Accepted 27-01-2020

Note

(c) 2020 by Balu Kuppusamy, Shivanshu Misra and Published by Siddharth Health Research and Social Welfare Society. This is an Open Access article licensed under a Creative Commons Attribution 4.0 International License https://creativecommons.org/licenses/by/4.0/ unported [CC BY 4.0]. 
The clinical features of bowel endometriosis vary depending on the extent and site of involvement. It is common during the premenopausal era when the endometrial cells are sensitive to hormonal changes during menstrual cycles. Investigations are often inconclusive in detecting the bowel endometriosis and the gold standard for diagnosis is laparoscopy. Once extrapelvic endometriosis has been identified, surgical treatment appears to result in a cure in over $95 \%$ of cases [6].

\section{Case Report}

A 42 years female, no comorbidities, with history of previous LSCS, complained of dysmenorrhea for the past 2 years associated with crampy abdominal pain. She had abdominal distension, loose stool and occasional vomiting during menstrual cycles, for the past 1 year. Symptoms started 2 days before cycles and persisted during menstruation. Patient had a history of $5 \mathrm{~kg}$ weight loss in one year. Gynecology evaluation did not reveal pelvic endometriosis.

Colonoscopy revealed non-negotiable stricture in the rectosigmoid region and biopsy was inconclusive. Axial imaging revealed rectosigmoid stricture and no pelvic endometriosis. Patient had presented with clinically recurrent low-grade intestinal obstruction. She was subjected to laparoscopic anterior resection and had an uncomplicated post-surgical recovery. Histology revealed no underlying malignancy, but confirmed colonic endometriosis.

A- Physical and examination: Patient had a BMI of $31.4 \mathrm{~kg} / \mathrm{m}$.2General examination was normal. Per-abdominal examination was soft with no mass or tenderness. Per vaginal examination showed normal cervix, normal sized anteverted uterus with free fornix.

B- Investigations: Routine blood investigations were normal. CA 125 and CEA were19.43U/ml and $4 \mathrm{ng} / \mathrm{ml}$ respectively. Trans-vaginal scan showed normal sized uterus with heterogenous myometrial echo suggestive of adenomyosis. Left ovary was in pouch of Douglas (POD) and both ovaries were normal in size and echo-structure. The patient was referred to the surgical department for the management of recurrent intestinal obstruction. On colonoscopy, it was found that a non-negotiable stricture, $22 \mathrm{~cm}$ from the anal verge with mucosal inflammation and extrinsic compression. There was a tight stricture with pin hole, and the scope could not be negotiated beyond. Mucosal biopsy revealed
Colonic mucosa with no significant pathology. CECT abdomen and MRI pelvis showed rectosigmoid stricture, no evidence of significant pelvic endometriosis. There were no lymph nodes seen.

\section{Outcome and follow-up}

On table findings: Diagnostic laparoscopy was performed. Dense adhesions were found between rectosigmoid, upper rectum and the uterus with a stricture at the rectosigmoid region. Few endometriotic spots were seen in the rectosigmoid surface. Both ovaries were relatively normal, left ovary being adherent in the POD. No deposits were observed in the pelvic wall or POD. After separation of pelvic adhesions, a non-table sigmoidoscopy was done. A non-negotiable and non-dilatable stricture was observed at the rectosigmoid junction. Gynecological opinion was obtained during the procedure. Owing to the recurrent subacute obstruction, minimal pelvic endometriosis and diagnosis being equivocal, laparoscopic anterior resection was done. Patient had an uneventful recovery. She is doing well and is on regular followups.

\section{Discussion}

Remorgida $\mathrm{V}$ et al studied bowel endometriosis and its presentation, diagnosis, and treatment. the majority of patients develop a variety of gastrointestinal complains. Several techniques have been proposed for the diagnosis of bowel endometriosis including double-contrast barium enema, transvaginal ultrasonography, rectal endoscopic ultrasonography, magnetic resonance imaging, and multi slice computed tomography enteroclysis.

Medical management of bowel endometriosis is currently speculative; expectant management should be carefully balanced with the severity of symptoms and the feasibility of prolonged follow-up. Several studies demonstrated an improvement in quality of life after extensive surgical excision of the disease. Bowel endometriotic nodules can be removed by various techniques: mucosal skinning, nodulectomy, full thickness disc resection, and segmental resection [6].

Koga $\mathrm{K}$ et al in their study to evaluated the usefulness of transvaginal and transrectal ultrasonography for diagnosis and management of deeply infiltrating rectosigmoid endometriosis. Transvaginal and transrectal ultrasonography provides characteristic appearances for rectosigmoid 
Endometriosis that correlate well with its histological findings and are useful in the management of rectosigmoid endometriosis [7].

Moawad NS et al did comparison of laparoscopic anterior discoid resection (ADR) and laparoscopic low anterior resection (LAR) of deep infiltrating rectosigmoid endometriosis. The ADR group had consistently higher increments of improvement in bowel symptoms and dyspareunia. Overall satisfaction rate with the procedures was $93.3 \%$. SF-12 scores were comparable between the 2 groups. ADR compared with LAR is associated with decreased operative time, blood loss, and hospital stay and a lower rate of anastomotic strictures. Other outcomes and satisfaction rates are comparable between the 2 procedures [8].

Cameron IC et al also studied intestinal endometriosis: presentation, investigation, and surgical management. Abdominal pain was the main presenting feature in 20 cases, with associated nausea and vomiting in 12 cases and altered bowel habit in ten. Other presenting features included rectal bleeding, abdominal bloating and tenesmus. Endometriosis was not suspected preoperatively in any of the patients without a past history of this condition.

Accurate preoperative diagnosis proved very difficult, with only laparoscopy providing definite evidence of intestinal endometriosis prior to formal surgery. Colonic resections were performed in 12 cases, small bowel resection in six cases and appendicectomy in nine cases, together with resection of adjacent adherent structures.

This series illustrates the difficulty of establishing an accurate preoperative diagnosis, and the propensity of intestinal endometriosis to mimic other gastrointestinal diseases, particularly carcinoma and inflammatory bowel disease [9].

A case report was presented by Tade AO. et al on chronic intestinal obstruction due to rectosigmoid endometriosis. This paper presents a case of chronic intestinal endometriosis in a young Nigerian woman presenting with features of chronic intestinal obstruction.

She was found to have a stricture in the rectosigmoid at laparotomy. Hartmann's resection was done. Histologically, the stricture was due to endometriosis. Subsequent closure of colostomy and re-establishment of intestinal continuity gave excellent results [10].
A similar case of sigmoid endometriosis in a postmenopausal woman leading to acute large bowel obstruction was reported by Bidarmaghz B et al. Distinguishing sigmoid endometriosis can be very difficult from other gastrointestinal pathologies as there are no pathognomonic symptoms of the disease. Mostly they are misdiagnosed as irritable bowel syndrome, inflammatory bowel disease, ischemic colitis or even malignancy.

Colonoscopy has limitation in revealing the nature of the obstruction as the mucosal biopsy from the narrowed site is normal and the stricture is due to pressure effect from the muscular coat and serosal involvement.

Barium enema or computed tomography may not reveal anything more than an extrinsic bowel compression and the ultimate diagnosis has to depend on the histopathology of resected stricture [11].

Yantiss RK et al evaluated challenges in clinical and pathologic evaluation on endometriosis of the intestinal tract. Synekidou $\mathrm{E}$ et al in a case study like ours presented the case of a 50-year-old female patient with endometriosis of the sigmoid colon and manifestations of bowel obstruction.

The most appropriate therapeutic approach demands a multidisciplinary team that includes a gynaecologist, a general surgeon and an expertise psychologist. Many other studies also support our observations [12-15].

\section{Conclusion}

Endometriosis, which is the implantation of endometrial tissue outside the uterus, affects one in ten women in their reproductive age. It is rare in post-menopausal women and extremely rare to cause large bowel obstruction due to isolated deposits in recto-sigmoid. Pre-operative diagnosis is often impossible and invariably depends on postoperative histological confirmation. In our patient, though history was suspicious of endometriosis due to cyclical nature of intestinal obstruction, rest all the evidence was suggestive of malignant stricture, until histopathology of resected specimen confirmed the diagnosis of recto-sigmoid endometrial deposits.

\section{Acknowledgements}

The authors would like to thank the hospital surgical and pathology department as well as the patient for all their help in preparing this article. 


\section{Reference}

01. Sampson JA. Metastatic or embolic endometriosis, due to the menstrual dissemination of endometrial tissue into the venous circulation. Am J Pathol. 1927;3(2)93110.

[Crossref]

02. Douglas C, Rotimi O. Extragenital endometriosis- a clinicopathological review of a Glasgow hospital experience with case illustrations. J Obstet Gynaecol. 2004;24(7)804808.

doi:[Article:https://doi.org/10.1080/014436104000 09568][Crossref]

03. Prystowsky JB, Stryker SJ, Ujiki GT, Poticha SM. Gastrointestinal endometriosis, Incidence and indications for resection. Arch Surg. $1988 ; 123(7) 855-858$.

doi:[Article:https://doi.org/10.1001/archsurg.1988.0 1400310069011][Crossref]

04. Giudice LC. Clinical practice Endometriosis. N Engl J Med. 2010;362(25)2389-2398.

doi:[Article:https://doi.org/10.1056/NEJMcp1000 274][Crossref]

05. Horton JD, Dezee KJ, Ahnfeldt EP, Wagner M. Abdominal wall endometriosis- a surgeon's perspective and review of 445 cases. Am J Surg. 2008;196(2)207-212.

doi:[Article:https://doi.org/10.1016/j.amjsurg.2007. 07.035][Crossref]

06. Remorgida V, Ferrero S, Fulcheri E, Ragni N, Martin DC. Bowel endometriosis- presentation, diagnosis, and treatment. Obstet Gynecol Sur. 2007;62(7)461-470.

doi:[Article:https://doi.org/10.1097/01.ogx.000026

8688.55653.5c][Crossref]

07. Koga K, Osuga $Y$, Yano T, Momoeda M, Yoshino $O$, Hirota $Y$, et al. in their study saw characteristic images of deeply infiltrating rectosigmoid endometriosis on transvaginal and transrectal ultrasonography. Hum Reprod. 2003;18(6)1328-1333.

doi:[Article:https://doi.org/10.1093/humrep/deg 243][Crossref]

08. Synekidou E, Arapoglou S, Tona N, Katsiki E, Tsiachris C, Dimitropoulou I, et al. Gastrointestinal endometriosis- a diagnostic challenge. Hellenic J Surg. 2015;87(5)423-426.

doi: [Article:https://doi.org/10.1007/s13126-0150250-1][Crossref]
09. Moawad NS, Guido R, Ramanathan R, Mansuria $S$, Lee T. Comparison of laparoscopic anterior discoid resection and laparoscopic low anterior resection of deep infiltrating rectosigmoid endometriosis. JSLS- J Soc Laparoendoscop Surg. 2011;15(3)331-338.

doi:[Article:https://doi.org/10.4293/108680811X13 125733356431][Crossref]

10. Sali PA, Yadav KS, Desai GS, Bhole BP, George A, Parikh SS, et al. Small bowel obstruction due to an endometriotic ileal stricture with associated appendiceal endometriosis- A case report and systematic review of the literature. Int J Surg Case Rep. 2016;23;163-168. doi:[Article:https://dx.doi.org/10.1016\%2Fj.ijscr. 2016.04.025][Crossref]

11. Cameron IC, Rogers S, Collins MC, Reed MW. Intestinal endometriosis- presentation, investigation, and surgical management. Int J Colorect Dis. 1995;10(2)83-86.

doi: [Article:https://doi.org/10.1007/bf00341202] [Crossref]

12. Tade AO. Chronic intestinal obstruction due to rectosigmoid endometriosis- a case report. Nigerian J Med- J Nat Assoc Res Doc Nigeria. $2006 ; 15(2) 165-166$.

doi:

[Article:http://doi.org/10.4314/njm.v15i2.37104]

[Crossref]

13. Yantiss RK, Clement PB, Young RH. Endometriosis of the intestinal tract- a study of 44 cases of a disease that may cause diverse challenges in clinical and pathologic evaluation. Am J Surg Pathol. 2001;25(4)445-454.

doi: [Article:https://doi.org/10.1097/00000478200104000-00003][Crossref]

14. Bidarmaghz B, Shekhar A, Hendahewa R. Sigmoid endometriosis in a post-menopausal woman leading to acute large bowel obstruction- a case report. Int J Surg Case Rep. $2016 ; 28 ; 65-67$.

[Article:https://doi.org/10.1016/j.jiscr.2016.09.008] [Crossref]

15. Sievert W, Sellin JH, Stringer CA. Pelvic endometriosis simulating colonic malignant neoplasm. Arch Int Med. 1989;149(4)935-938. doi:

[Article:https://doi.org/10.1001/archinte.1989.00390 040131028][Crossref] 